\title{
Chronic kidney disease can increase the risk of preoperative deep vein thrombosis in middle-aged and elderly patients with hip fractures
}

This article was published in the following Dove Press journal:

Clinical Interventions in Aging

\section{Zhen Wang \\ Ji Xiao \\ Zitao Zhang \\ Xusheng Qiu \\ Yixin Chen}

Department of Orthopedics, Drum Tower Hospital Clinical College of Nanjing University, Nanjing, China
Correspondence: Yixin Chen Department of Orthopedics, Drum Tower Hospital Clinical College of Nanjing University, 32I Zhongshan Road, Nanjing, Jiangsu 210008, P.R. China

Tel +86 I 5005149964

Email chenyixin93@I26.com
Background: Preoperative deep vein thrombosis (DVT) is a common complication in patients with hip fractures. Chronic kidney disease (CKD) as a frequent comorbidity in middle-aged and elderly patients with hip fractures is known to promote a proinflammatory and prothrombotic state. We aimed to identify whether CKD can increase the risk of DVT in middle-aged and elderly patients with hip fractures, as well as identify other risk factors.

Patients and methods: We retrospectively studied 248 middle-aged and elderly patients with hip fractures who were admitted to our hospital from January 2016 to June 2017, meeting all the inclusion criteria. Doppler ultrasonography was used to diagnose DVT. Patients with CKD were classified into five stages according to the Kidney Diseases Outcomes Quality Initiative. We identified whether CKD could increase the occurrence of preoperative DVT in middle-aged and elderly patients with hip fractures and further investigated other independent risk factors for preoperative DVT by using univariate and multivariate analyses.

Results: The mean estimated glomerular filtration rate was $125.7 \pm 41.4 \mathrm{~mL} / \mathrm{min} / 1.73 \mathrm{~m}^{2}$. Briefly, 82.3\% ( $n=204)$ had been diagnosed with normal kidney function, 11.7\% ( $n=29)$ with mildly decreased kidney function, and $6.0 \%(n=15)$ with stage 3 and $4 \mathrm{CKD}$. In addition, of the 248 patients, $11.7 \%(n=29)$ developed DVT before surgery. Independent predictors of preoperative DVT identified by multivariate analyses were age, prolonged bedridden time, increased levels of fibrinogen, and lower estimated glomerular filtration rate.

Conclusion: CKD can increase the risk rate of preoperative DVT in middle-aged and elderly patients with hip fractures. Additionally, age, prolonged bedridden time, and increased levels of fibrinogen were also independent risk factors for preoperative DVT in these patients. We should take preventive measures for these patients with risk factors in order to reduce the incidence of preoperative DVT.

Keywords: CKD, preoperative DVT, hip fractures, middle-aged and elderly patients

\section{Introduction}

As a common complication of osteoporosis, hip fractures are the leading cause of morbidity and mortality and are expected to affect up to 6.3 million individuals worldwide by $2050 .{ }^{1,2}$ Venous thrombus embolism (VTE) is one of the most common perioperative complications in patients with hip fractures. ${ }^{3}$ Recently, because of growing concerns regarding potentially lethal complications from fresh thrombus emboli, such as massive intraoperative pulmonary embolism, clinicians are more attentive to the diagnosis and prevention of preoperative deep vein thrombosis (DVT) after hip fractures. The American College of Chest Physicians recommended initiation of routine subcutaneous low-molecular-weight heparin (LMWH) therapy to prevent DVT, either 
from at least 12 hours before surgery or at least 12 hours after surgery. However, the incidence of preoperative DVT varies from $2.6 \%$ to $17.3 \%$, and was even found to be as high as $54 \%-62 \%$ in patients with hip fractures who experienced a delay in surgery by $>48$ hours. ${ }^{4-7}$ Until now, few studies have reported the risk factors of preoperative DVT, including female sex, subtrochanteric fractures, pulmonary diseases, previous VTE, long duration of immobilization, and increased levels of D-dimer. ${ }^{5,8}$ However, the combination of these risk factors cannot effectively predict DVT. Therefore, it is necessary to facilitate DVT prediction by identifying more risk factors.

Renal insufficiency is a common comorbid disease and is associated with a range of metabolic bone diseases; it is especially common among elderly patients with hip fractures. ${ }^{9}$ Renal insufficiency typically results in the occurrence of chronic kidney disease (CKD), and patients with CKD usually experience increased rates of morbidity and mortality. ${ }^{10}$ Autonomic dysfunction, myocyte dysfunction, altered electrolyte metabolism, and cardiac fibrosis may contribute to cardiovascular disease in patients with CKD, which is the leading cause of morbidity and mortality in this population. ${ }^{11}$ Furthermore, infection is also one of the most common causes of death in patients with CKD. ${ }^{12}$ Recently, it has been reported that patients with CKD have an increased risk for bleeding and considerable research has suggested a relation between DVT and CKD in the general population. ${ }^{13,14}$

To our best knowledge, no recent report has investigated whether CKD patients with hip fractures are more susceptible to developing preoperative DVT than those with normal kidney function. Based on serum creatinine levels, the estimated glomerular filtration rate (eGFR) is an improved measure of kidney function. Thus, we aimed to investigate the association of CKD reflected by eGFR, with the risk of DVT and mortality in a retrospective observational cohort study of patients with hip fractures. We also sought to identify other variables that might affect the rate of preoperative DVT.

\section{Patients and methods}

\section{Ethical statement}

Ethical approval was obtained from the Clinical Research Ethics Committee of Drum Tower Hospital Clinical College of Nanjing University. The subjects participated voluntarily in the study and consented to their data being used for research. Written informed consent was obtained from every eligible subject.

\section{Patients and data collection}

The inclusion criteria were as follows: 1) patients aged $\geq 45$ years; 2) those with fresh hip fractures that required open reduction internal fixations (ORIFs); 3) hospital stay of $>48$ hours duration; 4 ) those willing to undergo anticoagulant therapy and provided signed consent accordingly; and 5) those with available preoperative ultrasonography results. The exclusion criteria were as follows: 1) patients with hip fractures with delayed treatment (3 weeks from injury to surgery); 2) those with open soft tissue fractures; 3) those with severe organ insufficiency except kidney; 4) those with poor compliance; 5) and those who were unwilling to participate in the study. Owing to the long time gap between the fracture and operation, patients with delayed hip fractures were excluded. Because open soft tissue fractures are usually related to extensive damage and these patients were too few in number for meaningful statistical analysis, these injuries were also excluded. Moreover, to prevent side effects, patients with anticoagulation contraindications were excluded from the study. In total, 365 consecutive patients with identified hip fractures (femoral neck or trochanteric fractures) who underwent ORIF between January 2016 and June 2017 at our institution were screened. Finally, after applying the exclusion criteria, 248 patients with hip fractures were included for analysis.

All patients who were admitted to the hospital were routinely assessed regarding anticoagulation contraindications. Preoperative prophylactic anticoagulation regimen with LMWH or rivaroxaban (from the same company) was subcutaneously administered for patients without anticoagulation contraindications. The dosage administered was $0.3 \mathrm{~mL}$, once daily. In addition, mechanical thromboprophylaxis (pressure pump, 20 minutes twice a day) was used. Blood samples were collected on admission (2 hours after admission). We used Doppler ultrasonography to diagnose DVT. The diagnosis of DVT was made by two experienced radiologists and reviewed by one senior radiologist according to Rabinov and Paulin's criterion. ${ }^{15}$ All patients underwent ultrasonography in both lower limbs, a day before the planned surgery.

We collected baseline demographic characteristics of all patients, including age; sex; body mass index; hypertension; diabetes; heart disease; cerebrovascular disease; malignancy; smoking history; thrombosis history; prothrombin time; activated partial thromboplastin time; and serum levels of creatinine, blood urea nitrogen, C-reactive protein, fibrinogen, and D-dimer. Severity of CKD was graded as per the following five stages: stage 1 , eGFR $\geq 90 \mathrm{~mL} / \mathrm{min} / 1.73 \mathrm{~m}^{2}$ with risk 
factors; stage 2 , eGFR of $60-89 \mathrm{~mL} / \mathrm{min} / 1.73 \mathrm{~m}^{2}$ with evidence of renal injury; stage 3 , eGFR of $30-59 \mathrm{~mL} / \mathrm{min} / 1.73$ $\mathrm{m}^{2}$; stage 4 , eGFR of $15-29 \mathrm{~mL} / \mathrm{min} / 1.73 \mathrm{~m}^{2}$; and stage 5 , eGFR $<15 \mathrm{~mL} / \mathrm{min} / 1.73 \mathrm{~m}^{2}$ (the level at which dialysis or transplantation may be necessary). ${ }^{16}$ Values for GFR were estimated by using the modification of diet in renal disease equations that were based on Chinese patients with CKD: ${ }^{17}$ eGFR $\left(\mathrm{mL} / \mathrm{min} / 1.73 \mathrm{~m}^{2}\right)=186 \times$ plasma creatinine ${ }^{-1.154} \times$ age $^{-0.203} \times 0.742$ (if female) $\times 1.223$ (if Chinese).

\section{Data analysis}

STATA version 18.0 (SPSS Inc., Chicago, IL, USA) was used for statistical analysis. Continuous variables are presented as mean $\pm \mathrm{SD}$ and categorical variables as absolute numbers and proportions. The chi-squared test was used to analyze categorical data, and Student's $t$-test was used to analyze continuous variables. Factors with significant difference were included in logistic regression to generate adjusted odds ratios (ORs). We report ORs and 95\% CIs for the factors predicting preoperative DVT. A $P$-value of $<0.05$ was considered statistically significant for all analyses.

\section{Results}

\section{Patient characteristics}

A total of 248 patients (mean age, $71.8 \pm 13.7$ years; age range, 45-96 years; 140 women and 108 men) who underwent ORIFs were enrolled in this study, and all were treated with LMWH at admission. Of these patients, 135 had femoral neck fractures and 113 had trochanteric fractures.

\section{Classification of renal function}

The mean eGFR was $125.7 \pm 41.4 \mathrm{~mL} / \mathrm{min} / 1.73 \mathrm{~m}^{2}$. Of these 248 cases, $82.3 \%(n=204)$ had been diagnosed with normal kidney function, $11.7 \%(n=29)$ with mildly decreased kidney function, and $6.0 \%(n=15)$ with stage 3 and 4 CKD. In addition, the mean eGFR of patients with stage $3 / 4$ CKD was $38.0 \pm 15.3 \mathrm{~mL} / \mathrm{min} / 1.73 \mathrm{~m}^{2}$.

\section{Prevalence of DVT}

Of the 248 patients, $11.7 \%$ patients $(n=29)$ developed DVT before ORIFs. Proximal DVT was detected in 3 patients (1.2\%) and distal DVT in 26 patients $(10.5 \%)$. Of the proximal cases, one was in the femoral vein and the remaining two in the popliteal vein. Of the distal cases, ten involved $\geq 2$ veins and seven were close to the popliteal vein. No patient was diagnosed with fatal pulmonary embolism as a result of the DVT.
Table I Patient characteristics

\begin{tabular}{|c|c|c|c|}
\hline \multirow[t]{2}{*}{ Variables } & \multicolumn{2}{|c|}{ Total patients $(\mathrm{N}=\mathbf{2 4 8})$} & \multirow[t]{2}{*}{$P$-value } \\
\hline & $\begin{array}{l}\text { Without DVT } \\
(n=219)\end{array}$ & $\begin{array}{l}\text { With DVT } \\
(n=29)\end{array}$ & \\
\hline Age (years, mean $\pm S D$ ) & $79.6 \pm 13.7$ & $80.8 \pm 9.3$ & $<0.00 I^{\mathrm{a}}$ \\
\hline No of women & $12 \mid(55.3 \%)$ & 19 (65.5\%) & 0.325 \\
\hline BMI $\left(\mathrm{kg} / \mathrm{m}^{2}\right.$, mean $\left.\pm \mathrm{SD}\right)$ & $24.5 \pm 3.8$ & $25.3 \pm 4.1$ & 0.372 \\
\hline Hypertension & 75 (34.2\%) & II (37.9\%) & 0.683 \\
\hline Diabetes & 35 (16.0\%) & $6(20.7 \%)$ & 0.594 \\
\hline Heart disease & 39 (I7.8\%) & $9(31.0 \%)$ & 0.130 \\
\hline Cerebrovascular disease & 24 (1 I.0\%) & $5(17.2 \%)$ & 0.353 \\
\hline Malignancy & 7 (3.2\%) & $2(6.9 \%)$ & 0.284 \\
\hline Smoking history & 67 (30.6\%) & $10(34.5 \%)$ & 0.673 \\
\hline Thrombosis history & 25 (II.4\%) & 7 (24.1\%) & 0.073 \\
\hline $\begin{array}{l}\text { Bedridden time (days, } \\
\text { mean } \pm S D \text { ) }\end{array}$ & $5.2 \pm 3.3$ & $8.0 \pm 4.8$ & $0.005^{\mathrm{a}}$ \\
\hline PT (s) & $12.5 \pm 1.3$ & $12.7 \pm 1.0$ & 0.336 \\
\hline APTT (s) & $29.5 \pm 5.6$ & $29.4 \pm 3.5$ & 0.979 \\
\hline Fibrinogen (g/L) & $3.4 \pm 1.0$ & $4.5 \pm 2.7$ & $0.040^{\mathrm{a}}$ \\
\hline D-dimer (mg/L) & $8.8 \pm 9.1$ & $10.1 \pm 7.7$ & 0.443 \\
\hline CRP (mg/L) & $35.4 \pm 31.2$ & $42.6 \pm 31.4$ & 0.248 \\
\hline $\begin{array}{l}\text { eGFR }\left(\mathrm{mL} / \mathrm{min} / 1.73 \mathrm{~m}^{2}\right. \\
\operatorname{mean} \pm \mathrm{SD})\end{array}$ & $128.8 \pm 40.5$ & $102.5 \pm 42.0$ & $0.00 \mathrm{I}^{\mathrm{a}}$ \\
\hline
\end{tabular}

Note: $\mathrm{a}<0.05$ was considered statistically significant.

Abbreviations: APTT, activated partial thromboplastin time; BMI, body mass index; CRP, C-reactive protein; DVT, deep vein thrombosis; eGFR, estimated glomerular filtration rate; $\mathrm{PT}$, prothrombin time.

\section{Analysis of the potential factors}

In univariate analysis (Table 1$)$, only age $(P<0.001)$, bedridden time $(P=0.005)$, serum fibrinogen $(P=0.040)$, and eGFR $(P=0.001)$ were significantly associated with preoperative DVT. Multivariate logistic regression analysis (Table 2) identified four independent factors for preoperative DVT: age $(\mathrm{OR}=1.06, P=0.017)$, prolonged bedridden time $(\mathrm{OR}=1.17, P=0.001)$, increased levels of fibrinogen $(\mathrm{OR}=1.63, P=0.008)$, and lower eGFR $(\mathrm{OR}=0.99, P=0.046)$. Further, Table 3 shows that compared with individuals with eGFR of $90 \mathrm{~mL} / \mathrm{min} / 1.73 \mathrm{~m}^{2}$, the OR for preoperative DVT for those with stage 3/4 CKD was 2.18.

Table 2 Multivariate regression analysis of the relation between CKD and preoperative DVT in patients with hip fracture

\begin{tabular}{llll}
\hline Risk factors & OR & $\mathbf{9 5 \%} \mathbf{C l}$ & P-value \\
\hline Age & $\mathrm{I} .06$ & $\mathrm{I} .0 \mathrm{I}-\mathrm{I} . \mathrm{II}$ & $0.017^{\mathrm{a}}$ \\
Bedridden time & $\mathrm{I} .17$ & $1.06-1.28$ & $0.00 \mathrm{I}^{\mathrm{a}}$ \\
Fibrinogen & 1.63 & $1.14-2.35$ & $0.008^{\mathrm{a}}$ \\
eGFR & 0.99 & $0.98-1.00$ & $0.046^{\mathrm{a}}$ \\
\hline
\end{tabular}

Note: ${ }^{a}<0.05$ was considered statistically significant.

Abbreviations: CKD, chronic kidney dysfunction; DVT, deep vein thrombosis; eGFR, estimated glomerular filtration rate. 
Table 3 ORs for preoperative DVT by the level of eGFR after adjustment

\begin{tabular}{lllll}
\hline eGFR & Incidence & OR & $\mathbf{9 5 \%} \mathbf{C l}$ & $\boldsymbol{P}$-value \\
\hline$\geq 90^{\mathrm{a}}$ & $8.8 \%$ & 1.00 & $\mathrm{~N} / \mathrm{A}$ & $\mathrm{N} / \mathrm{A}$ \\
$60-89$ & $20.7 \%$ & 2.24 & $0.70-7.20$ & 0.177 \\
$<60$ & $33.3 \%$ & 2.18 & $1.08-4.43$ & $0.031^{\mathrm{a}}$ \\
\hline
\end{tabular}

Notes: ${ }^{a}$ Calculated as the reference for $O R . P<0.05$ was considered statistically significant.

Abbreviations: DVT, deep vein thrombosis; eGFR, estimated glomerular filtration rate: N/A, not applicable.

\section{Discussion}

To our best knowledge, this is the first study to investigate the relation between preoperative DVT and CKD in patients with hip fractures who underwent ORIFs. Patients with hip fractures are at an increased risk of DVT, especially those with pre-existing comorbidities. CKD has an increasing prevalence in the general population and is a frequent comorbidity in patients with hip fractures. ${ }^{918}$ In our study, the prevalence of patients with eGFR $<60 \mathrm{~mL} / \mathrm{min} / 1.73 \mathrm{~m}^{2}$ was $6.0 \%(\mathrm{n}=15)$, and our study showed that eGFR was an independent factor of preoperative DVT in patients with hip fractures. Patients with CKD had a higher increased risk of occurrence of preoperative DVT than those with normal kidney function, which was consistent with data from previous studies. ${ }^{19-21}$ Cavanaugh et $\mathrm{al}^{19}$ found that CKD and end-stage renal disease patients undergoing total joint arthroplasty had a greater risk of DVT $(\mathrm{OR}=1.38)$ than those without renal disease. By performing a retrospective study based on a cohort of 1,274 patients, $\mathrm{Li}$ et $\mathrm{al}^{20}$ found that $\mathrm{CKD}$ can increase the risk of both total and symptomatic DVT after total joint arthroplasty and the relative risk for DVT in patients with stage $3 / 4 \mathrm{CKD}$ was 2.68. Additionally, Lutz et $\mathrm{al}^{21}$ reported that the risk for thromboembolic disease was 2.5 times greater in mild renal dysfunction and 5.5 times greater in severe renal dysfunction than in patients with normal kidney function. However, few studies reported that there was no significant relationship between DVT and CKD. ${ }^{22,23}$ Considering our more accurate and sensitive diagnostic approach and criteria of preoperative DVT, we believe that the risk of DVT was correlated with CKD, which was consistent with most studies.

Although the mechanism linking higher preoperative DVT risk in CKD remains unclear, there are several possible explanations. Typically, patients with CKD always require hospitalization, which may have resulted in the association between CKD and provoked DVT. ${ }^{24}$ Furthermore, nephrotic syndrome and overt proteinuria are well-known risk factors for DVT. ${ }^{25,26}$ Mild-to-moderate CKD is associated with endothelial involvement, vascular injury, or related changes found in procoagulant proteins, such as increased levels of fibrinogen, von Willebrand factor, factor VII, factor VIII, and plasminogen activator inhibitor-1 or inflammatory markers. ${ }^{27-30}$ It is estimated that the elevated levels are due to increased synthesis in proportion to urinary losses. In our analysis, patients with DVT had higher levels of D-dimer, C-reactive protein, and fibrinogen than patients without DVT. However, only fibrinogen levels were significantly associated with preoperative DVT. Considering the small number of cases, larger studies with data on proteinuria are still required to evaluate the hemostatic mechanisms mediating the association between CKD and DVT.

In the present study, we identified three other independent predictive factors for preoperative DVT in patients with hip fractures - age, prolonged bedridden time, and increased fibrinogen level. Age is an endogenous factor and could not be modified. Long-time immobilization after injury is a well-accepted risk factor for preoperative DVT, which is consistent with previous studies. ${ }^{8,31}$ There are several variables that affect the time before surgery, including transfer from community hospitals, preoperative assessment, and optimization. While some of these variables can be manipulated, others cannot be. Even so, the surgery should be performed as soon as possible for patients with hip fractures after sufficient preoperative preparation. As we mentioned above, increased fibrinogen levels are associated with endothelial dysfunction, which may result in the occurrence of DVT. Additionally, many studies have reported that elevated fibrinogen levels show a significant association with DVT. ${ }^{32-35}$ In the regression analysis, we included smoking status, diabetes, malignancies, obesity, family history of VTE, and congestive heart failure. However, we did not observe their associations with preoperative DVT, likely because of the small numbers of these cases. Furthermore, they are usually considered as the most important risk factors for postoperative DVT, ${ }^{36}$ which may be different from preoperative DVT that we analyzed in this study. The relationship between these factors and preoperative VTE requires further study.

This study has several limitations. First, given that it was retrospective in design, many factors would have affected the accuracy of the study. Second, the number of patients was relatively small, and the clinical importance of our results would be understandably greater with larger sample sizes. Finally, considering the low number of patients with stage 3 and 4 CKD and mildly decreased kidney function, we did not further classify these patients, which limited the conclusions for this group. 


\section{Conclusion}

We found that CKD can increase the risk of preoperative DVT in patients with hip fractures. All patients with CKD should be given priority to receive preoperative thromboprophylaxis and investigation to rule out DVT. At the same time, we recommend a routine preoperative investigation for DVT in patients with other documented risk factors.

\section{Acknowledgment}

Funding was obtained from Nanjing Medical Science and Technique Development Foundation (JQX16021 and QRX17050).

\section{Disclosure}

The authors report no conflicts of interest in this work.

\section{References}

1. Cooper C, Campion G, Melton LJ. Hip fractures in the elderly: a worldwide projection. Osteoporos Int. 1992;2(6):285-289.

2. Roche JJ, Wenn RT, Sahota O, Moran CG. Effect of comorbidities and postoperative complications on mortality after hip fracture in elderly people: prospective observational cohort study. BMJ. 2005;331(7529):1374.

3. Mcnamara I, Sharma A, Prevost T, Parker M. Symptomatic venous thromboembolism following a hip fracture. Acta Orthop. 2009;80(6):687-692.

4. Cho YH, Byun YS, Jeong DG, Han IH, Park YB. Preoperative incidence of deep vein thrombosis after hip fractures in Korean. Clin Orthop Surg. 2015;7(3):298-302.

5. Shin WC, Woo SH, Lee SJ, Lee JS, Kim C, Suh KT. Preoperative prevalence of and risk factors for venous thromboembolism in patients with a hip fracture: an indirect multidetector CT venography study. J Bone Joint Surg Am. 2016;98(24):2089-2095.

6. Zahn HR, Skinner JA, Porteous MJ. The preoperative prevalence of deep vein thrombosis in patients with femoral neck fractures and delayed operation. Injury. 1999;30(9):605-607.

7. Lu Y, Ma B, Guo R, et al. Deep vein thrombosis in trauma: a prospective study of lower limb orthopedic trauma patients in Tianjin Hospital, China. Int Angiol. 2007;26(2):165-170.

8. Song K, Yao Y, Rong Z, Shen Y, Zheng M, Jiang Q. The preoperative incidence of deep vein thrombosis (DVT) and its correlation with postoperative DVT in patients undergoing elective surgery for femoral neck fractures. Arch Orthop Trauma Surg. 2016;136(10):1459-1464.

9. Najar MS, Mir MM, Muzamil M. Prevalence of osteoporosis in patients with chronic kidney disease (stages 3-5) in comparison with age- and sex-matched controls: a study from Kashmir Valley Tertiary Care Center. Saudi J Kidney Dis Transpl. 2017;28(3):538-544.

10. Go AS, Chertow GM, Fan D, Mcculloch CE, Hsu CY. Chronic kidney disease and the risks of death, cardiovascular events, and hospitalization. N Engl J Med. 2004;351(13):1296-1305.

11. Deo R, Sotoodehnia N, Katz R, et al. Cystatin C and sudden cardiac death risk in the elderly. Circ Cardiovasc Qual Outcomes. 2010;3(2): 159-164.

12. Cheikh Hassan HI, Tang M, Djurdjev O, Langsford D, Sood MM, Levin A. Infection in advanced chronic kidney disease leads to increased risk of cardiovascular events, end-stage kidney disease and mortality. Kidney Int. 2016;90(4):897-904.

13. Mahmoodi BK, Gansevoort RT, Veeger NJ, et al. Microalbuminuria and risk of venous thromboembolism. JAMA. 2009;301(17):1790-1797.

14. Ocak G, Vossen CY, Lijfering WM, et al. Role of hemostatic factors on the risk of venous thrombosis in people with impaired kidney function. Circulation. 2014;129(6):683-691.
15. Rabinov K, Paulin S. Roentgen diagnosis of venous thrombosis in the leg. Arch Surg. 1972;104(2):134-144.

16. Levey AS, Eckardt KU, Tsukamoto Y, et al. Definition and classification of chronic kidney disease: a position statement from Kidney Disease: Improving Global Outcomes (KDIGO). Kidney Int. 2005;67(6):2089-2100.

17. Ma YC, Zuo L, Chen JH, et al. Modified glomerular filtration rate estimating equation for Chinese patients with chronic kidney disease. J Am Soc Nephrol. 2006;17(10):2937-2944.

18. Corsonello A, Pedone C, Lattanzio F, et al. Chronic kidney disease and 1-year survival in elderly patients discharged from acute care hospitals: a comparison of three glomerular filtration rate equations. Nephrol Dial Transplant. 2011;26(1):360-364.

19. Cavanaugh PK, Chen AF, Rasouli MR, Post ZD, Orozco FR, Ong AC. Complications and mortality in chronic renal failure patients undergoing total joint arthroplasty: a comparison between dialysis and renal transplant patients. J Arthroplasty. 2016;31(2):465-472.

20. Li Q, Dai B, Yao Y, Song K, Chen D, Jiang Q. Chronic kidney dysfunction can increase the risk of deep vein thrombosis after total hip and knee arthroplasty. Biomed Res Int. 2017;2017:8260487-6.

21. Lutz J, Jurk K, Schinzel H. Direct oral anticoagulants in patients with chronic kidney disease: patient selection and special considerations. Int J Nephrol Renovasc Dis. 2017;10:135-143.

22. Königsbrügge O, Lötsch F, Zielinski C, Pabinger I, Ay C. Chronic kidney disease in patients with cancer and its association with occurrence of venous thromboembolism and mortality. Thromb Res. 2014;134(1):44-49.

23. Miric A, Inacio MC, Namba RS. The effect of chronic kidney disease on total hip arthroplasty. J Arthroplasty. 2014;29(6):1225-1230.

24. Mahmoodi BK, Gansevoort RT, Næss IA, et al. Association of mild to moderate chronic kidney disease with venous thromboembolism: pooled analysis of five prospective general population cohorts. Circulation. 2012;126(16):1964-1971.

25. Mahmoodi BK, Ten Kate MK, Waanders F, et al. High absolute risks and predictors of venous and arterial thromboembolic events in patients with nephrotic syndrome: results from a large retrospective cohort study. Circulation. 2008;117(2):224-230.

26. Singhal R, Brimble KS. Thromboembolic complications in the nephrotic syndrome: pathophysiology and clinical management. Thromb Res. 2006;118(3):397-407.

27. Kario K, Matsuo T, Kobayashi H, et al. Factor VII hyperactivity and endothelial cell damage are found in elderly hypertensives only when concomitant with microalbuminuria. Arterioscler Thromb Vasc Biol. 1996;16(3):455-461.

28. Dubin R, Cushman M, Folsom AR, et al. Kidney function and multiple hemostatic markers: cross sectional associations in the multi-ethnic study of atherosclerosis. BMC Nephrol. 2011;12:3.

29. Shlipak MG, Fried LF, Stehman-Breen C, Siscovick D, Newman AB. Chronic renal insufficiency and cardiovascular events in the elderly: findings from the Cardiovascular Health Study. Am J Geriatr Cardiol. 2004;13(2):81-90.

30. Migliacci R, Becattini C, Pesavento R, et al. Endothelial dysfunction in patients with spontaneous venous thromboembolism. Haematologica. 2007;92(6):812-818.

31. Geerts WH, Code KI, Jay RM, Chen E, Szalai JP. A prospective study of venous thromboembolism after major trauma. $N$ Engl J Med. 1994;331(24):1601-1606.

32. Koster T, Rosendaal FR, Reitsma PH, van der Velden PA, Briët E, Vandenbroucke JP. Factor VII and fibrinogen levels as risk factors for venous thrombosis. A case-control study of plasma levels and DNA polymorphisms - the Leiden Thrombophilia Study (LETS). Thromb Haemost. 1994;71(6):719-722.

33. Austin H, Hooper WC, Lally C, et al. Venous thrombosis in relation to fibrinogen and factor VII genes among African-Americans. J Clin Epidemiol. 2000;53(10):997-1001.

34. Kamphuisen PW, Eikenboom JC, Vos HL, et al. Increased levels of factor VIII and fibrinogen in patients with venous thrombosis are not caused by acute phase reactions. Thromb Haemost. 1999;81(5):680-683. 
35. Walton BL, Byrnes JR, Wolberg AS, Fibrinogen WAS. Fibrinogen, red blood cells, and factor XIII in venous thrombosis. J Thromb Haemost. 2015;13(Suppl 1):S208-S215.
36. Zhang BF, Wei X, Huang H, et al. Deep vein thrombosis in bilateral lower extremities after hip fracture: a retrospective study of 463 patients. Clin Interv Aging. 2018;13:681-689.

\section{Publish your work in this journal}

Clinical Interventions in Aging is an international, peer-reviewed journal focusing on evidence-based reports on the value or lack thereof of treatments intended to prevent or delay the onset of maladaptive correlates of aging in human beings. This journal is indexed on PubMed Central, MedLine,
CAS, Scopus and the Elsevier Bibliographic databases. The manuscript management system is completely online and includes a very quick and fair peer-review system, which is all easy to use. Visit http://www.dovepress. com/testimonials.php to read real quotes from published authors. 